\title{
OPTIMASI PENJADWALAN SIDANG SKRIPSI JURUSAN TEKNIK ELEKTRO PROGRAM STUDI TEKNIK INFORMATIKA POLITEKNIK NEGERI MALANG
}

\author{
Alfian Dwi Cahyo ${ }^{1}$, Imam Fahrur $\mathrm{R}^{2}$, Rudy Ariyanto ${ }^{3}$ \\ 1,2 Jurusan Teknik Elektro, Program Studi Teknik Informatika, Politeknik Negeri Malang \\ ${ }^{1}$ vian.jrs@gmail.com, ${ }^{2}$ imam.rozi@gmail.com, ${ }^{3}$ rudy@polinema.ac.id
}

\begin{abstract}
Abstrak
Dwi Cahyo, Alfian. 2014. Optimasi Penjadwalan Sidang Skripsi Jurusan Teknik Elektro Program Studi Teknik Informatika Politeknik Negeri Malang. Skripsi, Program Studi Teknik Informatika. Jurusan Teknik Elektro. Politeknik Negeri Malang. Pembimbing :(I) Imam Fahrur Rozi,ST.,MT, (II) Rudy Ariyanto,ST. MCs

Pada saat ini pembuatan jadwal sidang skripsi di Jurusan Elektro Program Studi Teknik Informatika masih dibuat secara manual oleh koordinator skripsi. Pembuatan jadwal tersebut membutuhkan waktu yang banyak dalam pemilihan dosen penguji agar tidak bentrok. Dengan memiliki suatu aplikasi berupa optimasi penjadwalan sidang tentu saja sangat bermanfaat dan memberikan keuntungan-keuntungan pada koordinator sidang.. Maka dari itu perlu dibuat sebuah aplikasi untuk membantu koordinator skripsi dalam pembuatan jadwal tersebut. Pembuatan optimasi penjadwalan sidang skripsi ini mengadopsi aturan yang telah dibuat oleh koordinator sidang skripsi kemudian dimasukkan ke dalam dalam bahasa php. Pada proses penjadwalan tersebut pembagian ruang,waktu,mahasiswa dan dosen dilakukan secara otomatis oleh sistem. Jadi dosen pembimbing tidak boleh menguji mahsiswa yang dibimbingnya, salah satu dosen pembimbing harus hadir pada saat mahasiswa yang dibimbingnya tersebut melakukan sidang. Dosen penguji sidang tersebut tidak boleh menguji di ruang yang lain pada sesi yang sama. Pemilihan ruang, waktu, mahasiswa serta dosen penguji diacak oleh sistem denga. Hasil pengujian menunjukkan bahwa sistem ini berhasil membuat penjadwalan sidang skripsi secara otomatis dan hasil penjadwalan sidang tersebut telah memenuhi peraturan yang telah dibuat oleh koordinator sidang skripsi. Sehingga optimasi penjadwalan sidang skripsi yang telah dibuat sudah optimal.
\end{abstract}

Kata Kunci : Penjadwalan, Optimasi, Penjadwalan Sidang

\section{Pendahuluan}

Informasi merupakan salah satu kebutuhan di dalam suatu instansi, perusahaan, organisasi, lembaga serta lingkungan yang berada di luar sistem. Informasi dianggap sangat penting karena dengan adanya informasi dapat menambah pengetahuan, mengurangi ketidakpastian dan resiko kegagalan serta dapat membantu para pemimpin dalam mengambil suatu kesimpulan dan keputusan yang efektif dan efisien.

Salah satu informasi yang penting bagi Politeknik Negeri Malang adalah tentang pembuatan Laporan Akhir dan Skripsi dikarenakan hal tersebut merupakan syarat mutlak bagi mahasiswa agar dapat memperoleh gelar Ahli Madya dan Sarjana.

Pada saat ini proses penjadwalan yang berhubungan dengan Skripsi di Politeknik masih belum optimal. Mulai dari pengumpulan nama judul, jadwal proses sidang, pemilihan nama dosen penguji, pembagian ruang sidang dan hal - hal lain yang berhubungan dengan Skripsi.

Optimasi Penjadwalan Sidang Skripsi adalah cara baru dalam pengolahan jadwal sidang Skripsi. Aplikasi ini berguna untuk memudahkan koordinator atau dosen panitia sidang skripsi dalam pembuatan jadwal sidang skripsi. 
Maka dari itu aplikasi sangat berguna bagi koordinator atau dosen panitia sidang skripsi. Merujuk pada permasalahan-permasalahan dan potensi yang ada, pengembangan dan penelitian ini bertujuan untuk membangun sebuah aplikasi yang berbasis web. Berdasarkan hal tersebut di atas, judul yang diambil pada penelitian ini adalah "Optimasi Penjadwalan Sidang Skripsi di Jurusan Teknik Elektro Program Studi Teknik Informatika Politeknik Negeri Malang”.

\section{Teori Dasar}

\section{A. Optimasi}

Menurut Suprodjo dan Purwandi, 1982, bahwa secara matematis optimasi adalah cara mendapatkan harga ekstrim baik maksimum atau minimum dari suatu fungsi tertentu dengan faktor-faktor pembatasnya. Jika persoalan yang akan diselesaikan dicari nilai maksimumnya, maka keputusannya berupa maksimasi. Optimasi dalam penyelesaian masalah merupakan suatu cara pengambilan keputusan sehingga didapatkan hasil penyelesaian yang optimal sesuai dengan kendala "state of nature" yang harus dipenuhi. Metode yang banyak digunakan antara lain Calculus, Dinamic Programming, Linear

Programming, Geomatrydan Inventory Theory (Hiller dan Liberman, 1982)

Linear Programming adalah salah satu teknis analisis dari kelompok teknik riset operasional yang menggunakan model matematik. Tujuannya adalah untuk mencari, memilih dan menentukan alternatif yang terbaik dari antara sekian alternatif grafis dan metode analisis secara aljabar (metode simpleks) (Nasedi dan Anwar, 1985).

Soekarwati (1995) menyebutkan dalam Linear Programming terdapat 3 (tiga) persyaratan dalam pengoptimalan suatu persoalan, yaitu :

Dalam program linear harus ada fungsi tujuan yang dinyatakan dalam persamaan garis lurus funsi $\mathrm{Z}$ atau $\mathrm{f}(\mathrm{Z})$ yaitu sesuatu yang dimaksimumkan atau yang diminimumkan.

$\mathrm{Z}=\mathrm{C}_{1} \mathrm{X}_{1}+\mathrm{C}_{2} \mathrm{X}_{2}+\ldots+\mathrm{C}_{\mathrm{n}} \mathrm{X}_{\mathrm{n}}$

Ket :

$\mathrm{X}=$ Aktivitas

$\mathrm{C}=$ Koefisien harga

Dalam program linear harus ada fungsi kendala yang dinyatakan dengan persamaan garis lurus :
$\mathrm{a}_{11} \mathrm{x}_{11}+\mathrm{a}_{22} \mathrm{x}_{22}+\ldots+\mathrm{a}_{\mathrm{n} 1} \mathrm{x}_{\mathrm{n} 1}$
$\geq \mathrm{b} 1$
$\mathrm{a}_{12} \mathrm{x}_{12}+\mathrm{a}_{22} \mathrm{x}_{22}+\ldots+\mathrm{a}_{\mathrm{n} 2} \mathrm{x}_{\mathrm{n} 2}$
$\geq \mathrm{b} 2$
$\mathrm{a}_{1 \mathrm{~m}} \mathrm{x}_{1 \mathrm{~m}}+\mathrm{a}_{2 \mathrm{~m}} \mathrm{x}_{2 \mathrm{~m}}+\ldots+\mathrm{a}_{\mathrm{nm}} \mathrm{x}_{\mathrm{nm}}$
$\geq \mathrm{b}$

Semua nilai $\mathrm{x}$ adalah positif atau sama dengan nol, dengan kata lain tidak boleh ada nilai $\mathrm{x}$ yang negatif. Dengan demikian, besarnya nilai koefisien input-output tidak boleh negatif $\left(\mathrm{x}_{1} \mathrm{x}_{2}, \ldots, \mathrm{x}_{\mathrm{n}}>0\right)$. Problem program linear dapat di rumuskan dengan bantuan model matematika atau dengan kata lain diskribsi problem linear dapat ditetapkan dengan menggunamkan hubungan yang disebut straight line ataulinear. Persamaan yang dapat di selesaikan dengan menggunakan Linear Programming adalah untuk mengoptimalkan dengan keterbatasan sumber daya yang dinyatakan dalam persamaan $(=)$ atau ketidaksamaan $(<$ atau $>)$. Dalam metode simpleks perhitungan rutinnya adalah sebagai proses berulang yang artinya kembali lagi dan kembali lagi, mulai dari awal menjamin kepada kita selalu bergerak lebih tertutup kepada jawaban optimum dan akhirnya metode ini menunjukkan pemecahan optimum telah dicapai.

\section{B. Penjadwalan}

Penjadwalan merupakan alokasi dari sumber daya terhadap waktu untuk menghasilkan sebuah kumpulan pekerjaan. Penjadwalan dibutuhkan untuk memproduksi order dengan pengalokasian sumber daya yang tepat, seperti mesin yang digunakan, jumlah operator yang bekerja, urutan pengerjaan part, dan kebutuhan material. Dengan pengaturan penjadwalan yang efektif dan efisien, perusahaan akan dapat memenuhi order tepat pada due date serta kualitas yang telah ditentukan. Penjadwalan diperlukan ketika beberapa pekerjaan harus diproses pada suatu mesin tertentu yang tidak bisa memproses lebih dari satu pekerjaan pada saat yang sama. Penjadwalan yang baik akan memaksimumkan efektivitas pemanfaatan setiap sumber daya yang ada, sehingga penjadwalan merupakan kegiatan yang penting dalam perencanaan dan pengendalian produksi. Tahap perencanaan dan tahap implementasi dari kegiatan penjadwalan merupakan masalah yang kompleks. (Baker ,1974).

Beberapa tujuan dari aktivitas penjadwalan, yaitu yang pertama adalah meningkatkan utilisasi penggunaan sumber daya, atau dengan kata lain mengurangi waktu tungu dari sumber daya tersebut, sehingga total waktu proses dapat berkurang dan produktivitasnya dapat meningkat. Kedua, mengurangi work-in-process (barang setengah jadi), yaitu mengurangi rata-rata jumlah pekerjaan yang menunggu dalam antrian proses ketika sumber daya yang ada masih mengerjakan tugas lain, dan yang ketiga, mengurangi keterlambatan, yaitu menjamin pemenuhan due date. Setiap pekerjaan mempunyai due date masing-masing dan terdapat penalti apabila pekerjaan tersebut selesai setelah due date seharusnya. sehingga akan meminimasi biaya keterlambatan.

Permasalahan penjadwalan yang sebenarnya biasanya sangat kompleks, sehingga biasanya tidak disusun solusi yang memenuhi ketiga tujuan di atas. Terdapat berbagai jenis aturan dan algoritma dalam menjadwalkan produksi. Akan tetapi tidak ada algoritma terbaik yang dapat menghasilkan solusi optimal dalam menyusun penjadwalan produksi. Sehingga biasanya algoritma penjadwalan disusun berdasarkan sistem permasalahan di dunia nyata dan memenuhi sejumlah batasan-batasan yang ada. (Bedworth et al,1987)

Algoritma penjadwalan dengan menentukan ukuran batch atau pembagian batch produksi pada tiap order konsumen yang dapat meminimumkan banyaknya 
persedian barang setengah jadi pada gudang WIP dengan meminimasi total actual flow time, dengan berdasarkan pada pendekatan algoritma Ras (2002) dalam menentukan ukuran dan jumlah batch tersebut. Pada penelitian ini, pengembangan algoritma penjadwalan yang dilakukan tidak mempertimbangkan tahap insersi (penambahan) jadwal, apabila terdapat permintaan yang baru masuk ke dalam perusahaan. Selain itu, jenis mesin yang digunakan juga mesin tunggal karena pengujian data hanya dilakukan pada satu sel mesin tertentu yang tidak mencakup pemilihan jumlah mesin. (Rahmawati ,2009)

Kondisi common due date dapat diartikan kondisi order yang akan dikerjakan mempunyai due date yang sama. Pada kenyataan praktek di lapangan, banyak perusahaan yang mengalami kondisi order pesanan yang akan dikerjakan mempunyai due date yang berbeda-beda. Kondisi order dengan due date yang berbeda-beda ini dinamakan kasus multi due date. Berdasarkan penelitian - penelitian sebelumnya, maka dapat dilihat terdapat peluang penelitian dengan melakukan penjadwalan batch pada job shop dengan kelompok mesin parallel yang mempertimbangkan due date yang berbeda-beda untuk tiap produknya (multi due date), dan dapat dilakukan insersi (penambahan) jadwal, apabila terdapat permintaan yang baru masuk ke dalam perusahaan. Kriteria performansi yang digunakan adalah dengan meminimasi total actual flow time(Zainudin Zukhri, 2014)

\section{Perancangan Sistem}

\section{A. Use Case Diagram}

Terdapat 1 aktor yang terlibat dalam use case diagram optimasi penjadwalan sidang skripsi ini yaitu admin yang ditunjukkan pada gambar 3.1 berikut :

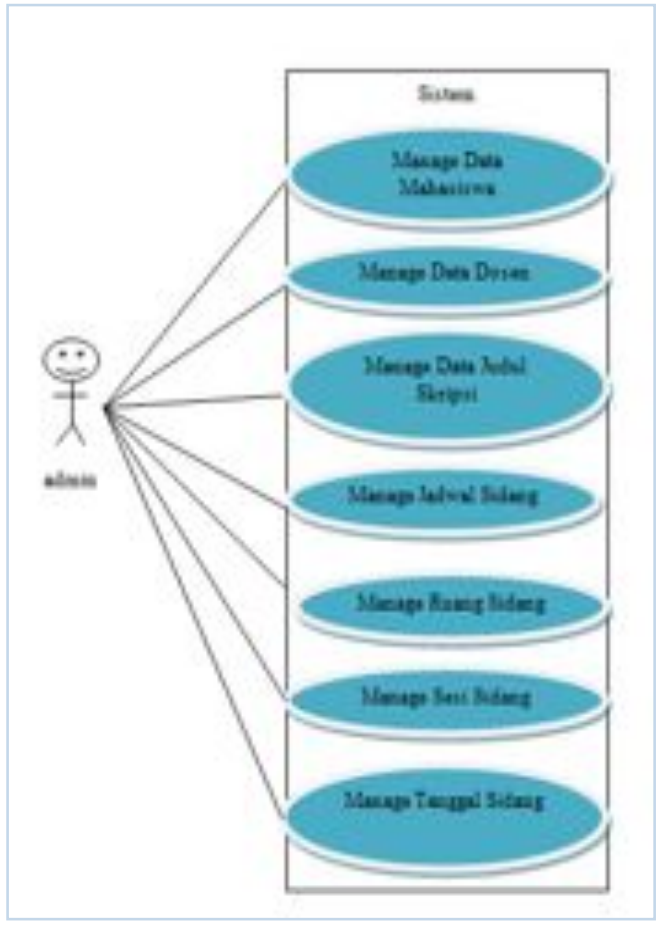

Gambar 3.1 Usecase Diagram

\section{B. Work Breakdown Structure}

Gambar di bawah ini adalah tentang work breakdown optimasi penjadwalan sidang skripsi yang ditunjukkan dengan gambar 3.2 :

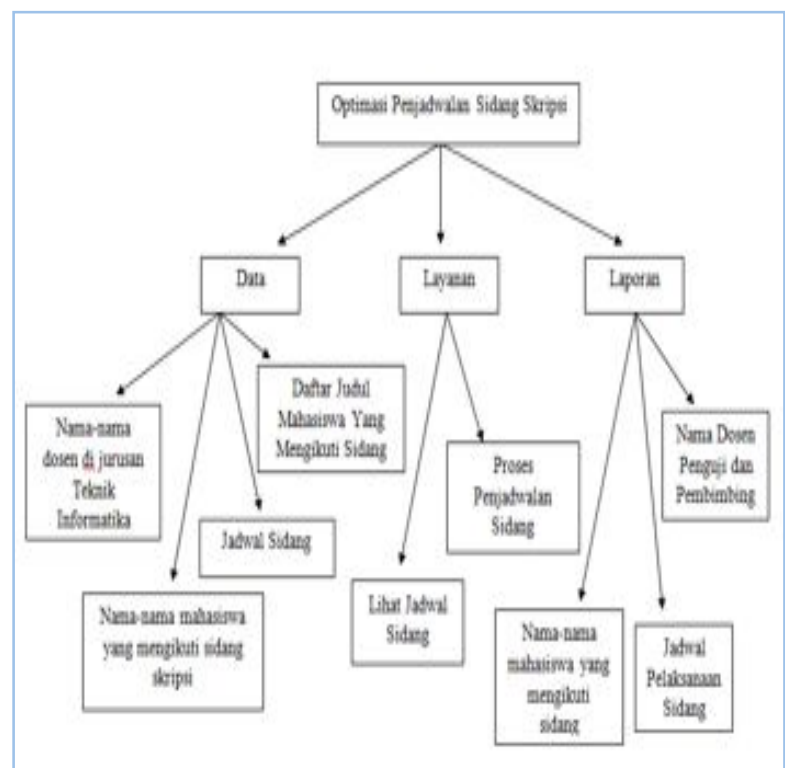

Gambar 3. 2. Work breakdown System

\section{Hasil}

\section{Halaman Utama SILADS PSTI}

Halaman ini merupakan tampilan awal dari Sistem Informasi sebelum login sebagai user atau admin. 


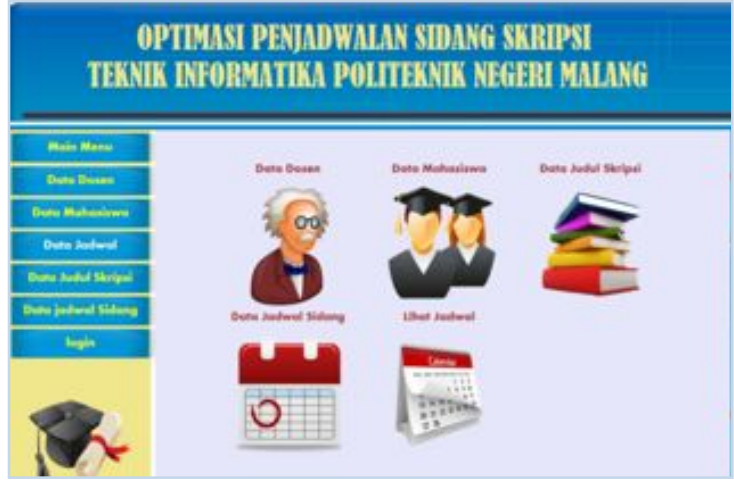

Gambar 4.1 Halaman Utama

2. Menu Login Admin

Tampilan dibawah adalah tampilan dari menu login admin

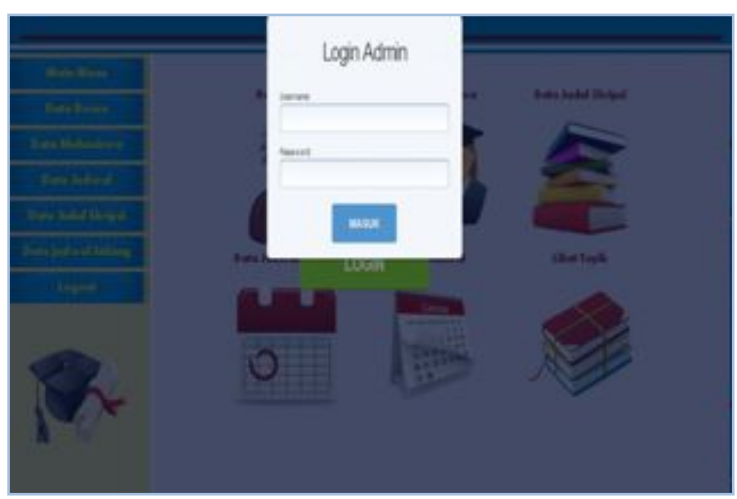

Gambar 4.2 Halaman Login Admin

\section{Halaman Setelah Login}

Tampilan pada gambar merupakan halaman setelah login admin

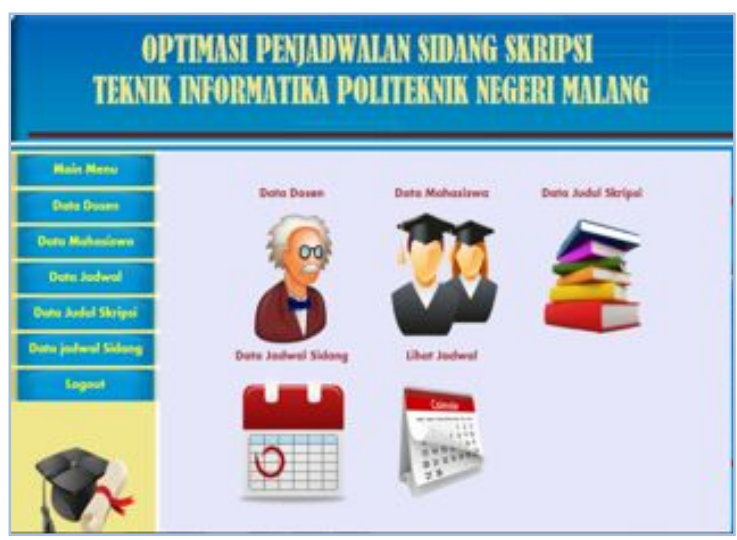

Gambar 4.3 Halaman Setelah Login

\section{Halaman Data Dosen}

Gambar dibawah merupakan tampilan dari menu data dosen

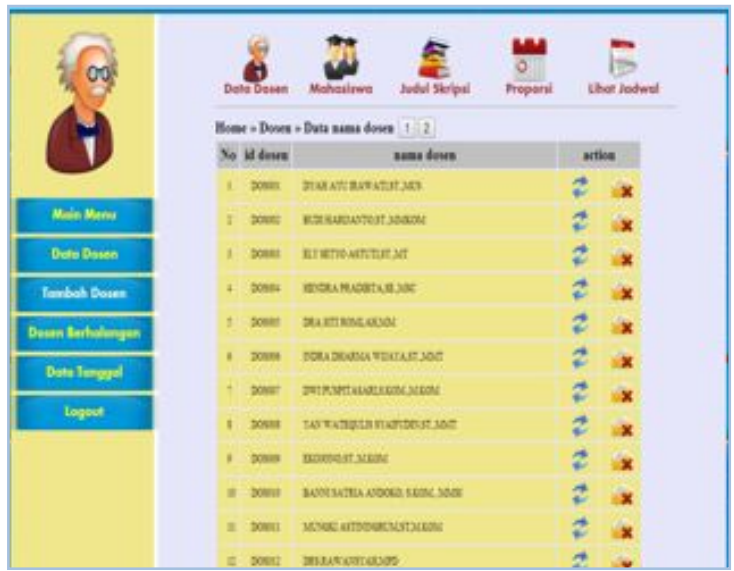

\section{Gambar 4.4 Data Dosen}

5. Halaman Data Mahasiswa

Gambar dibawah merupakan tampilan dari menu mahasiswa.

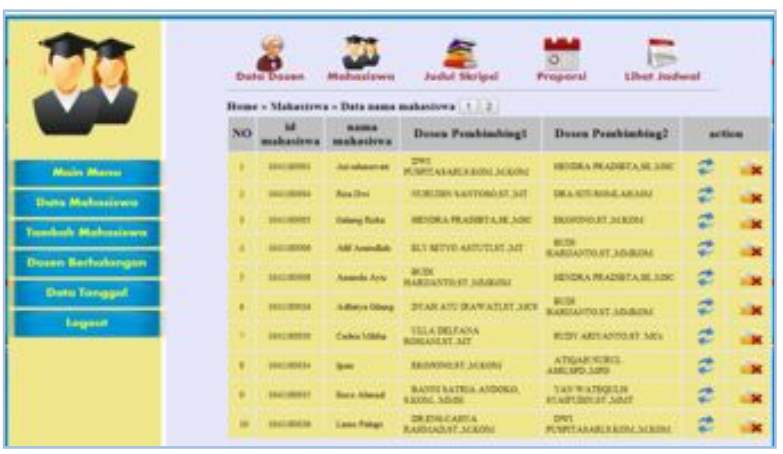

Gambar 4.5 Data Mahasiswa

6. Halaman Proses Jadwal

Gambar di bawah adalah gambar dari proses jadwal

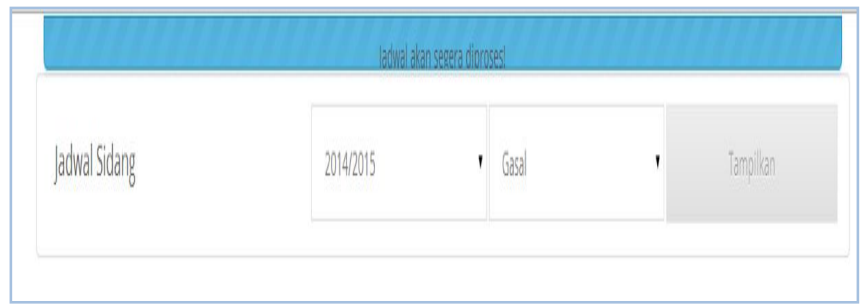

Gambar 4.6 Halaman Proses Jadwal

7. Halaman Lihat Jadwal

Gambar di bawah ini adalah merupakan hasil dari penjadwalan 


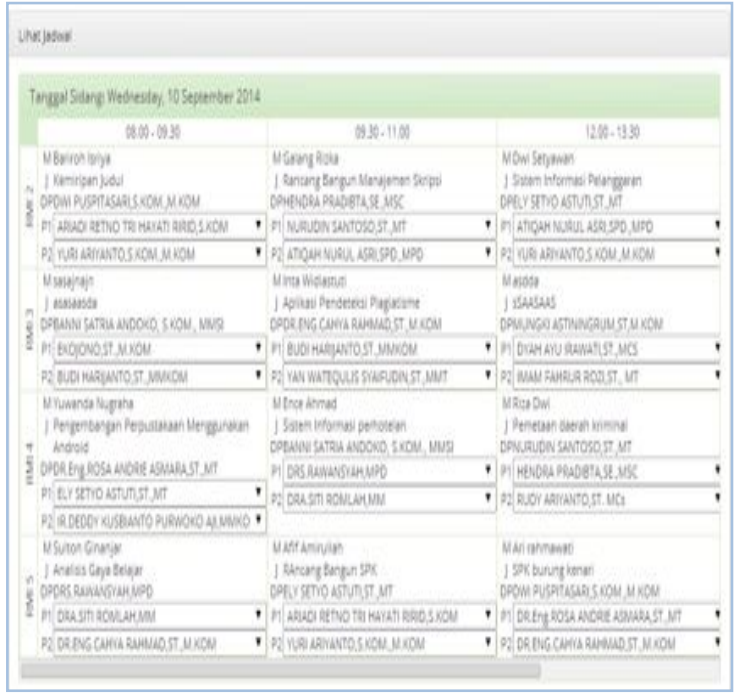

Gambar 4.7 Halaman Lihat Jadwal

\section{Halaman Hasil Sidang}

Ini adalah tampilan dari hasil sidang skripsi

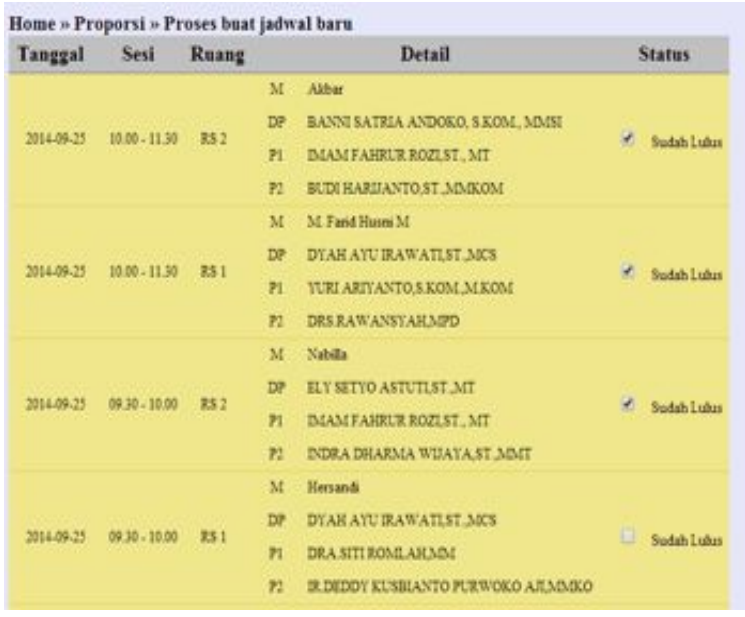

\section{Gambar 4.8 Halaman Hasil Sidang}

\section{Pembahasan}

Setelah melakukan pengujian pada tahap selanjutnya membahas hasil pengujian yang didapat pada saat penelitian. Perbandingan antara penjadwalan yang dibuat oleh sistem menggunakan dengan penjadwalan yang telah dibuat oleh koordinator sidang. Pada penjadwalan yang dibuat oleh sistem, tidak ada dosen penguji yang bentrok dengan mahasiswa yang dibimbingnya dalam satu sesi. Jadi dosen penguji tersebut dapat mendampingi mahasiswa yang dibimbingnya pada saat mahasiswa tersebut maju sidang. Pada gambar 6.6 adalah penjadwalan sidang skripsi yang dibuat oleh koordinator. Pada gambar tersebut tidak ada nama dosen penguji yang menguji pada saat sidang dilaksanakan serta tidak ada nama pembimbing yang mendampingi mahasiswa saat mahasiswa tersebut melakukan sidang.

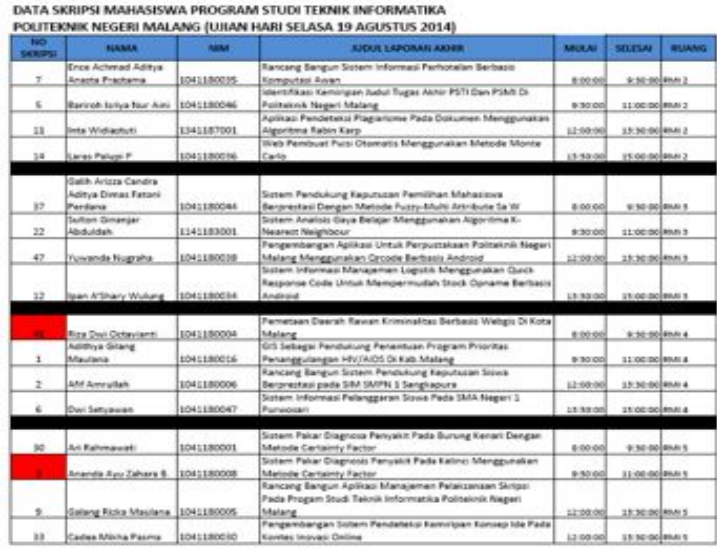

Gambar 5.1 Jadwal yang dibuat koordinator

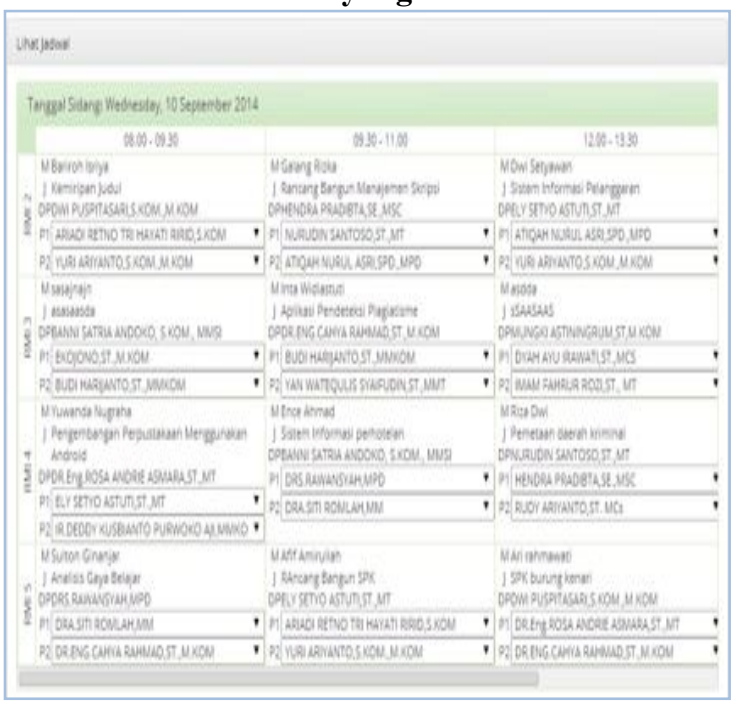

Gambar 5.2 Jadwal yang dibuat sistem

Pada gambar 5.2 menunjukkan hasil penjadwalan yang dibuat oleh sistem dalam satu sesi. Pada gambar diatas mahasiswa yang bernama Inta Widiastuti dengan pembimbing Dr. Eng Cahya Rahmad, ST,.M.KOM pada sesi sidang jam 08.00 - 09.30. Dosen Pembimbing Inta tersebut tidak menjadi dosen penguji di ruang yang lain dalam satu sesi pada saat Inta melakukan sidang. Jadi dosen pembimbing Inta tersebut dapat mendampingi Inta pada saat Inta melaksanakan sidang. Kemudian penguji Inta tersebut tidak menguji di tempat yang lain pada sesi yang sama. Sedangkan penjadwalan yang dibuat oleh koordinator terkadang ada dosen penguji yang bentrok dengan mahasiswa yang dibimbingnya melaksanakan sidang. Jadi dosen pembimbing tersebut tidak dapat mendampingi mahasiswa yang dibimbingnya. Seharusnya penjadwalan yang dibuat itu dosen pembimbing tidak boleh menjadi penguji pada saat mahasiswa yang dibimbingnya melakukan sidang.Dengan adanya proses penjadwalan yang dilakukan oleh sistem dapat membantu koordiantor dalam membuat sidang. Koordinator tidak perlu bingung menyusun jadwal sidang. 


\section{Kesimpulan dan Saran}

Setelah menganalisa dan merancang serta mengimplementasikan pembuatan Optimasi Penjadwalan Sidang Skripsi, maka didapat kesimpulan dan saran sebagai berikut :

\section{A. Kesimpulan}

Berdasarkan hasil penelitian dapat disimpulkan sebagai berikut :

1. Optimasi Penjadwalan Sidang Skripsi ini sudah diimplementasikan berbasis web menggunakan PHP dan telah berhasil menyelesaikan kasus penjadwalan.

2. Optimasi Penjadwalan Sidanng Skripsi ini sudah dibuat dengan mengadopsi peraturan yang dibuat oleh koordinator sidang dan hasil penjadwalan sidang skripsi sudah bisa dikatakan optimal dikarenakan telah memenuhi peraturan yang telah dibuat oleh koordinator sidang skripsi.

B. Saran

1. Pada sistem ini masih banyak kekurangan, hasil penilaian sidang masih belum ada untuk penelitian selanjutnya diharapkan menambahkan hasil penilaian yang dilakukan oleh dosen penguji.

2. Penjadwalan pada sistem ini masih menangani penjadwalan tanpa melihat jadwal perkuliahan dosen dan mahasiswa, diharapkan untuk pengembangan selanjutnya sistem dapat menangani jadwal sidang skripsi dengan melihat jadwaljadwal perkuliahan dosen dan mahasiswa akan dijadwalkan.

3. Pada sistem penjadwalan ini proses pembebanan dosen penguji masih belum ada, diharapkan nantinya yang mengembangkan sistem ini akan menambahkan proses pembebanan dosen penguji sesuai keahlian dosen pengujian yang disesuaikan dengan judul mahasiswa yang mengikuti sidang.

\section{Daftar Rujukan}

Ashinta.2009. AplikasiPenjadwalan Skripsi. Skripsi padaUniversitas Kristen Satya Wacana Salatiga. Kadir, Abdul 2000, Konsep danTuntunanPraktis Basis Data, Andi, Yogyakarta.

Peranginangin, Kasiman. 2006, Aplikasi Web dengan PHP dan MySQL .Andi Offset : Yogyakarta. R Rizal Isnanto, Aghus Sofwan, Arnold Fernando Sinaga. 2009. Perancangan Aplikasi Agenda ujian Tugas Akhir Berbasis Web. Skripsi pada Universitas Dipenogoro Semarang.

Sidik, Betha. (2005). MySQL Untuk Pengguna, Administrator, dan Pengembang Aplikasi web.Bandung:Informatika Bandung

Suyanto. (2008). Evolutionary Computation: Komputasi Berbasis Evolusi dan Genetika. Bandung:Informatika

Suyanto. (2008). Evolutionary Computation: Komputasi Berbasis Evolusi dan Genetika. Bandung: Informatika.

Witarto.2004, Memahami Sistem Informasi.Bandung: Informatika.

Zukhri, Zainudin.2014. Algoritma Genetika, Metode Komputasi Evolusioner untuk Menyelesaikan Masalah Optimasi. AndiPublisher : Yogyakarta. 